\title{
Validation of ozone profile retrievals derived from the OMPS LP version 2.5 algorithm against correlative satellite measurements
}

Natalya A. Kramarova et al.

Correspondence to: Natalya A. Kramarova (natalya.a.kramarova@nasa.gov)

The copyright of individual parts of the supplement might differ from the CC BY 4.0 License. 

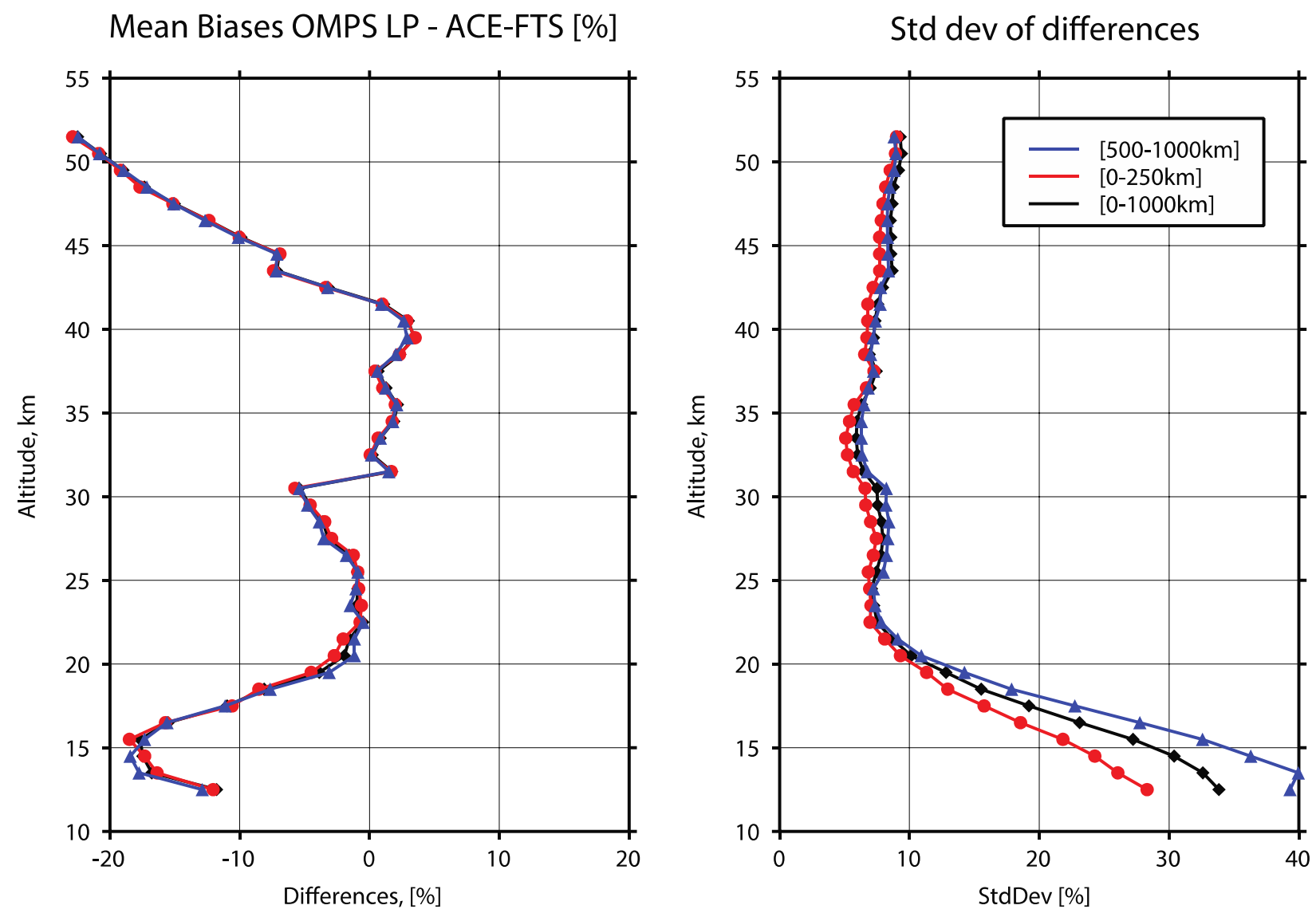

Figure S1. Left panel shows ozone mean differences between OMPS LP and ACE-FTS for three different colocation criteria: 0-1000 km in black (used in this study), 0-250 km in red, and 500-1000 km in blue. Right panel demonstrates corresponding $1 \sigma$ standard deviation for the differences. Mean differences do not significantly change depending on the collocation criteria, but the spread of the differences reduces for the stricter collocation criteria. This effect is especially pronounced in the lower stratosphere. 

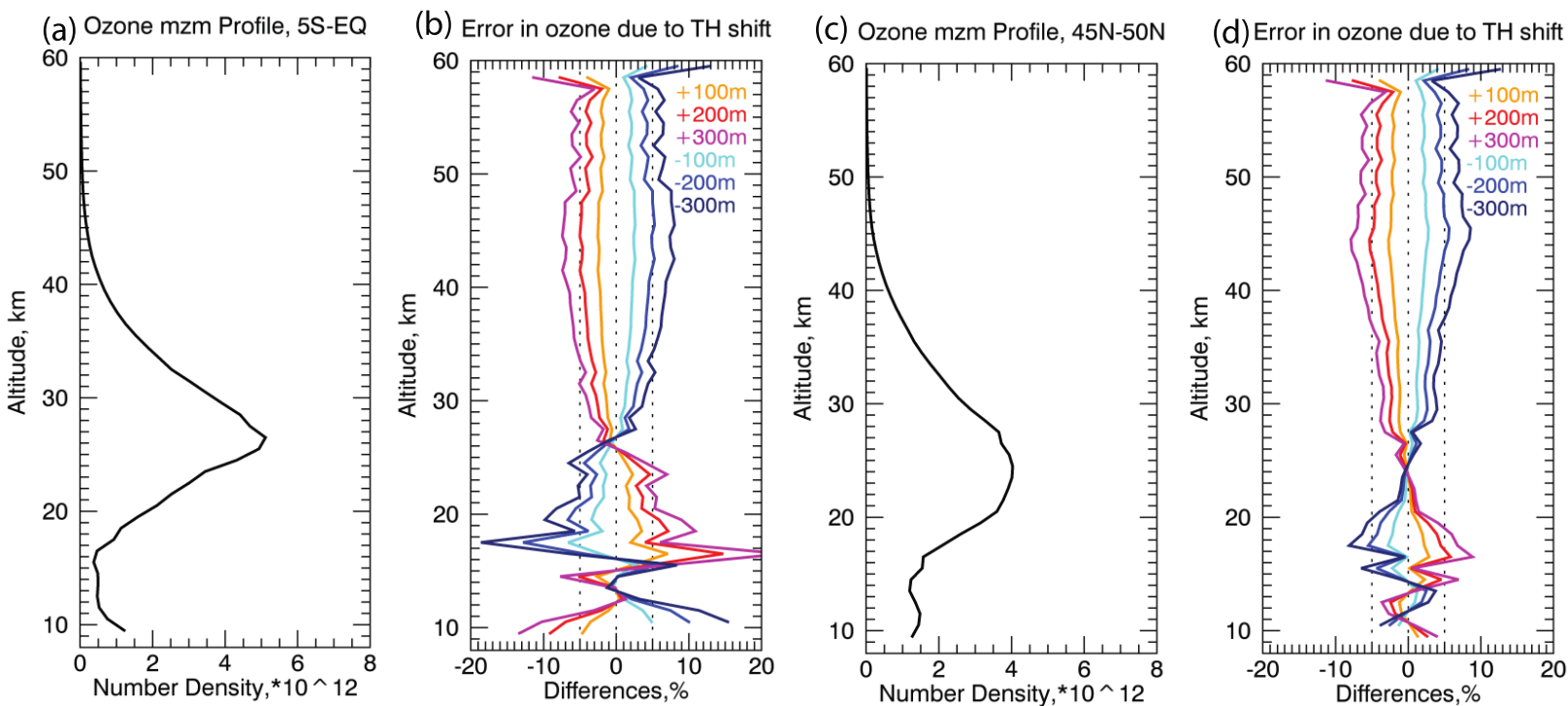

Figure S2. Vertical patterns of error in ozone due to a shift in the sensor altitude registration. Typical ozone profiles in the tropics (a) and mid-latitudes (c) are shifted by 100/200/300 meters up and down and the differences relative to the original profiles are shown in the tropics (b) and mid-latitudes (d). The differences are negligibly small near the ozone peak and increase above and below the peak with the switch of sign near the peak. Because the natural ozone variability is typically very small in the middle and upper stratosphere $(<5 \%)$, it is easy to detect a consistent bias in ozone due to error in the altitude registration. The bias will have the same sign and almost the same amplitude at altitudes above $35 \mathrm{~km}$. 


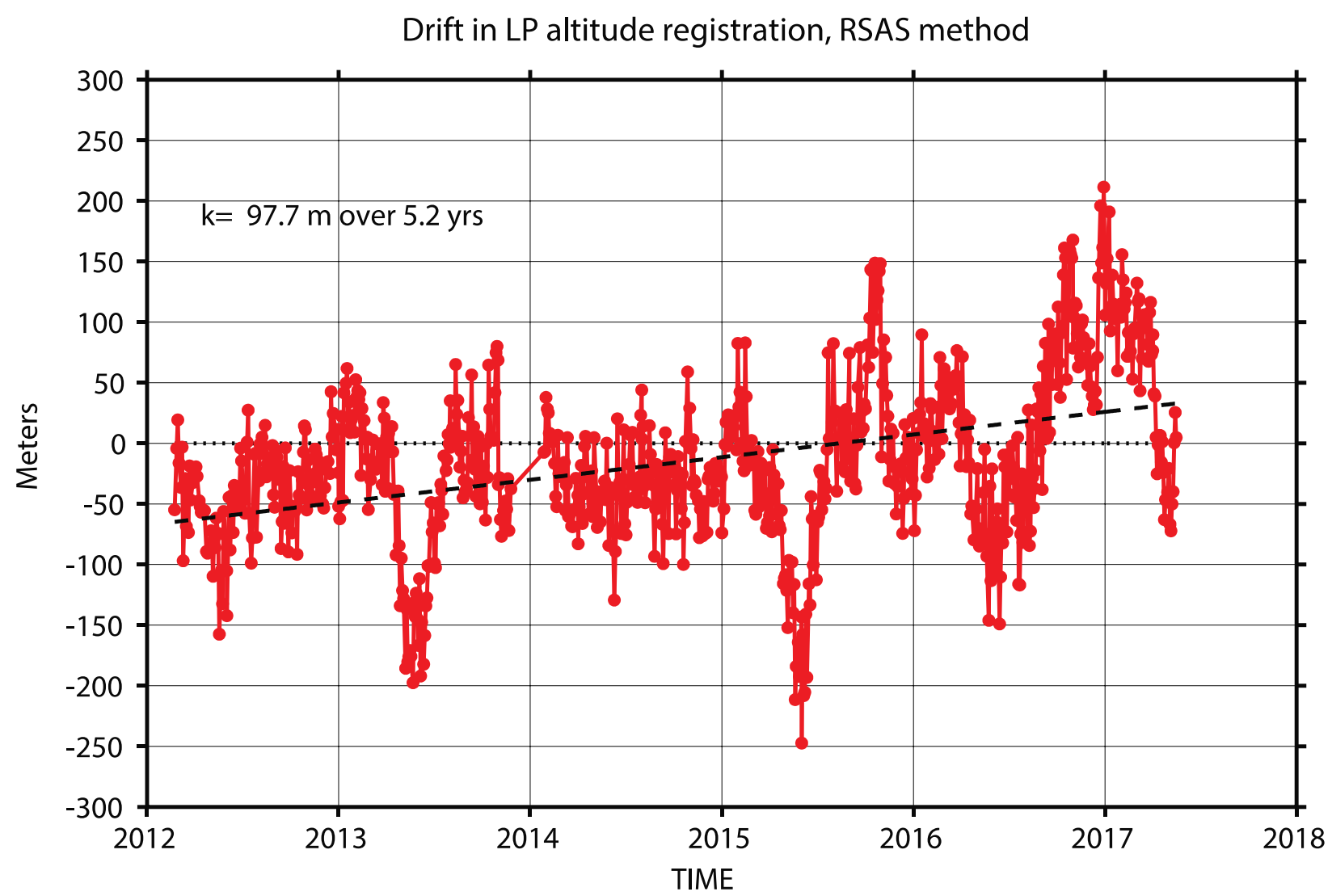

Figure S3. Time series of LP version 2.5 radiance residuals, derived from the RSAS altitude registration method (Moy et al., 2017), converted in meters. The radiances are averaged over 10 consecutive, along orbit measurements (events 40-50) over the southern mid- latitudes. These results show that there is an upward trend in the $L P$ altitude registration of order $\sim 100 \mathrm{~m}$ over 5.2 years. 

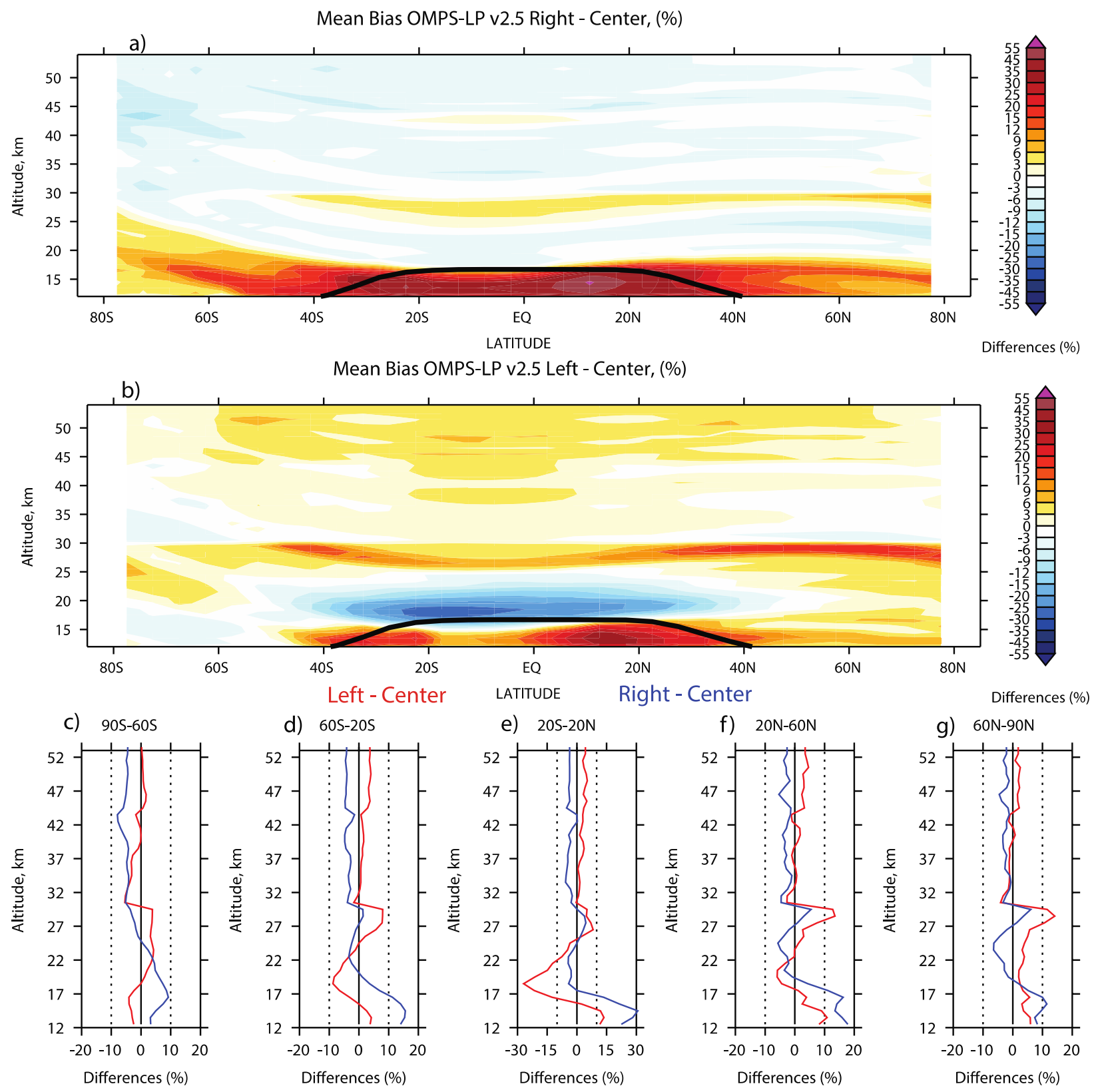

Figure S4. Mean biases among the three OMPS LP slits. The upper panel (a) shows the bias between right and center slits as a function of latitude and altitude (on $5^{\circ}$ latitude grid). Middle panel (b) presents the bias between left and center slits. The lower panels (c-g) show vertical structures of differences between left and center slits in red and right and center slits in blue in five wide latitude bins. 

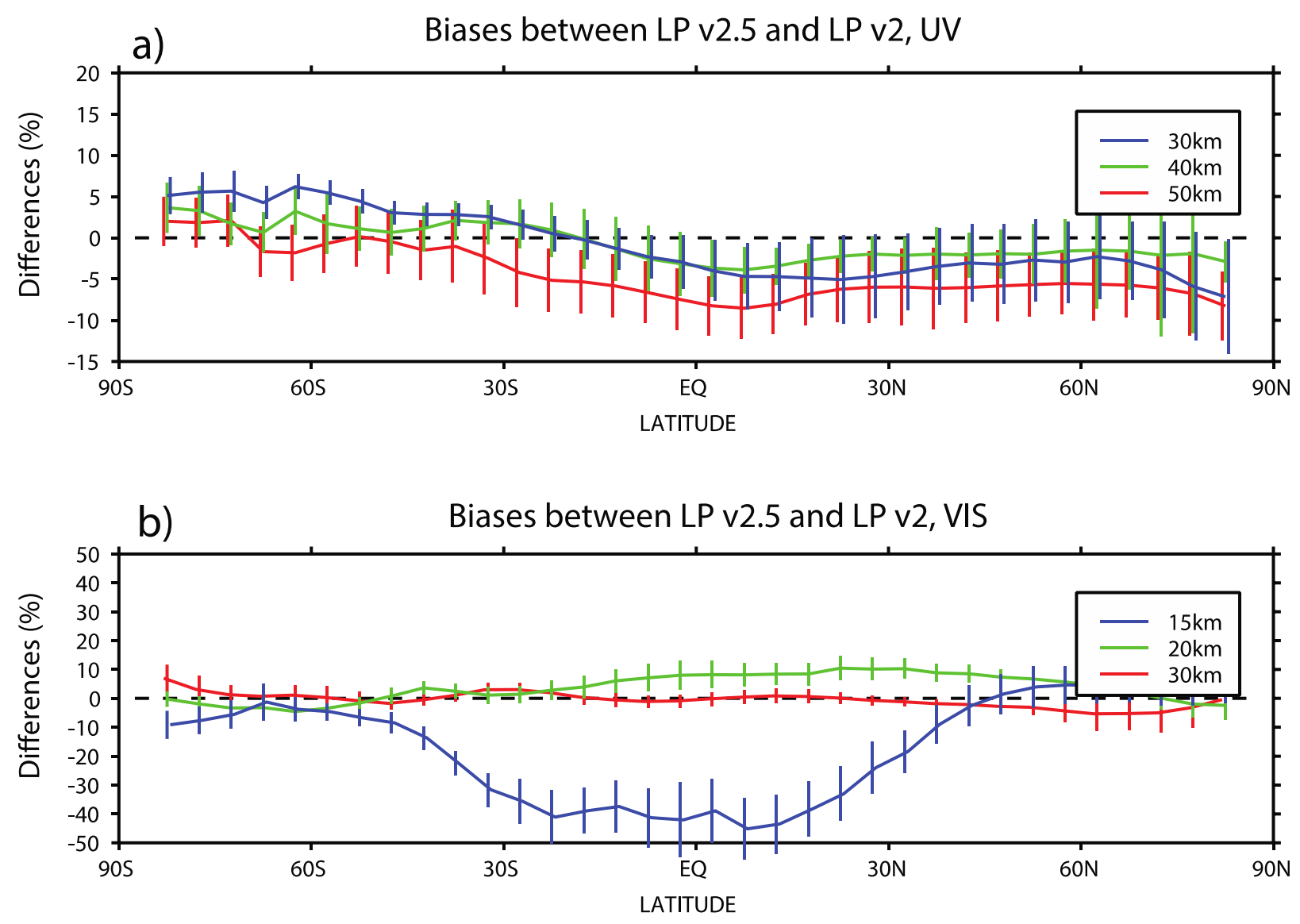

Figure S5. Mean biases between two recent OMPS LP versions (version 2.5 and version 2) as functions of latitude at several altitude levels. Upper panel shows differences for the UV retrievals at $30.5 \mathrm{~km}, 40.5 \mathrm{~km}$ and $50.5 \mathrm{~km}$, while lower panel shows differences for the VIS retrievals at $15.5 \mathrm{~km}, 20.5 \mathrm{~km}, 30.5 \mathrm{~km}$. Vertical error bars show $1 \sigma$ standard deviations for the differences. 


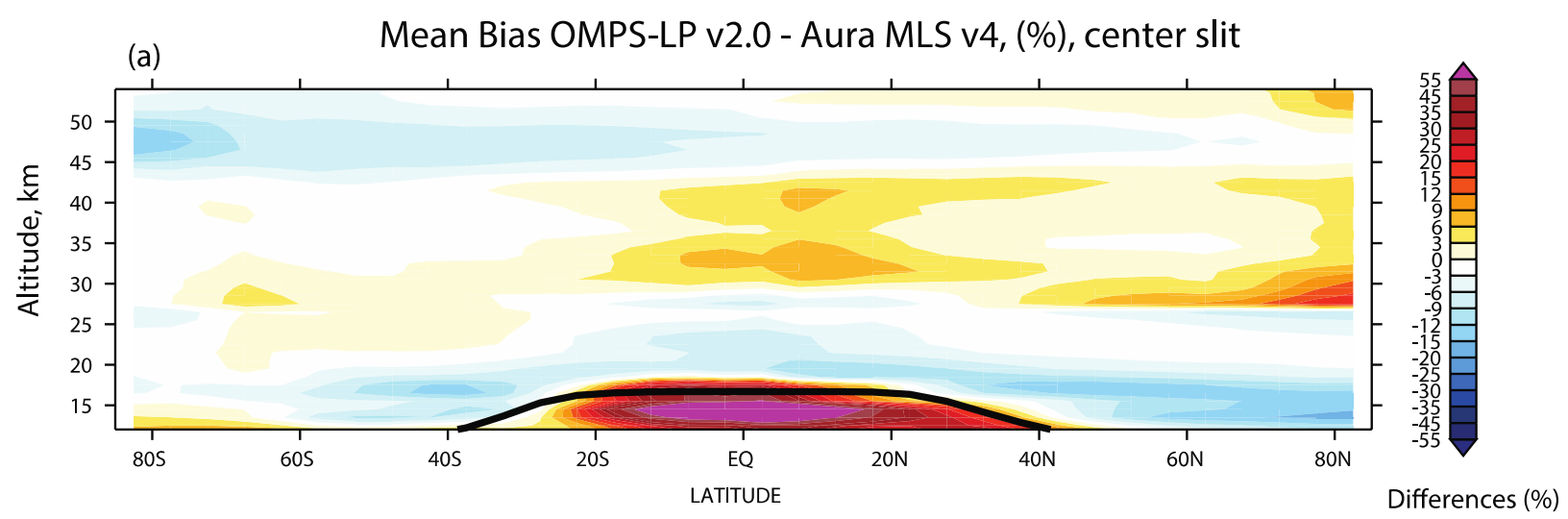

(b)

Biases between UV LP V2 and MLS v4
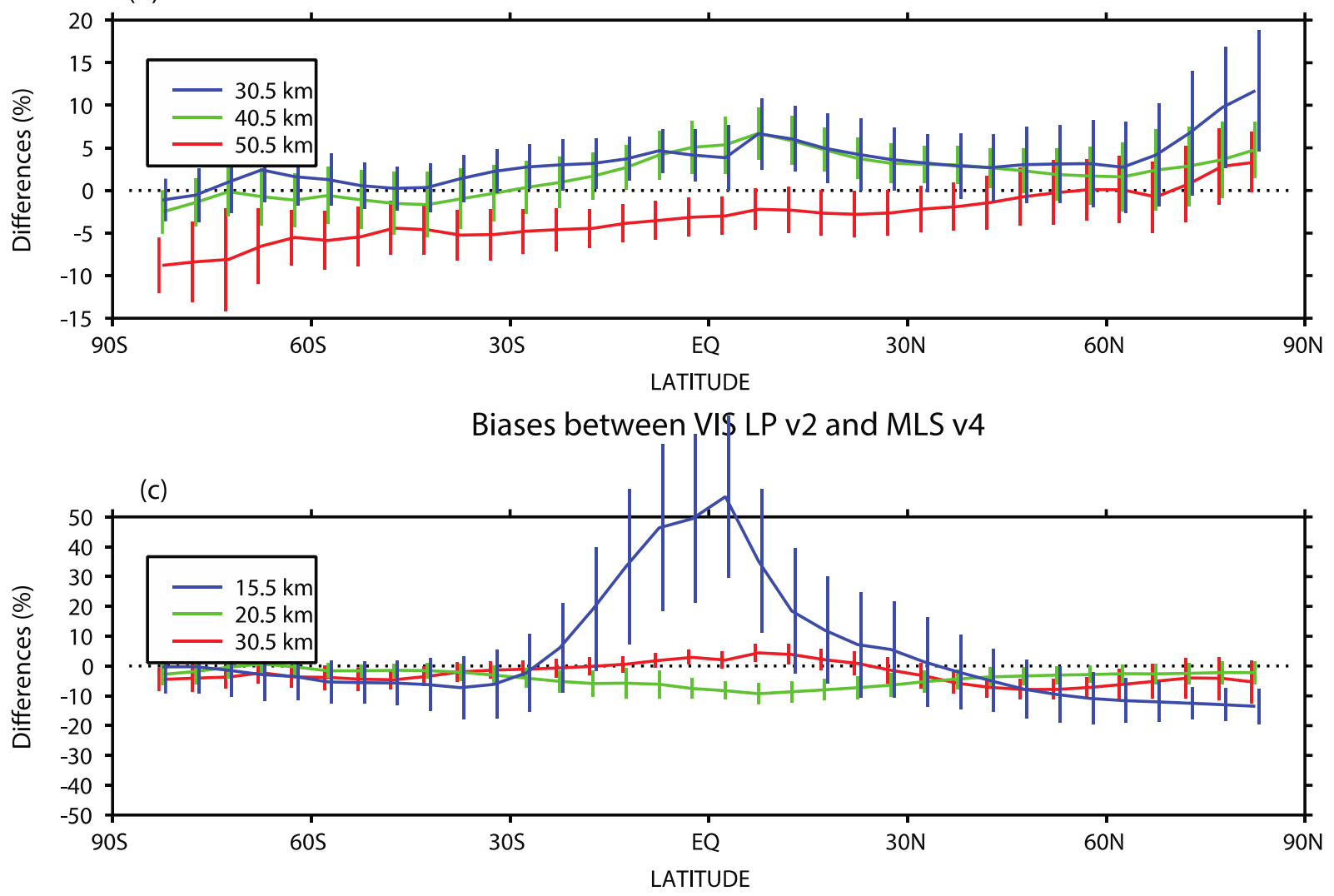

Figure S6. Mean biases between LP version 2 and Aura MLS version 4. Upper panel (a) shows the bias as a function of latitude and altitude (on $5^{\circ}$ latitude grid). The middle panel (b) shows mean differences as functions of latitude at three altitude levels for the UV ozone retrievals, and the lower panel (c) shows biases for the VIS retrievals. Vertical error bars indicate $1 \sigma$ standard deviations. In version 2 we observed a large positive bias (up to $100 \%$ ) against MLS in the lower stratosphere due to neglecting of aerosol attenuation. There is also a clear latitudinal dependence of the biases in the upper altitudes. 
Ozone $04 / 24 / 2013,[64 \mathrm{~S}, 84 \mathrm{~W}], \mathrm{dt}=1.2$ hours, dist $=36.5 \mathrm{~km}$

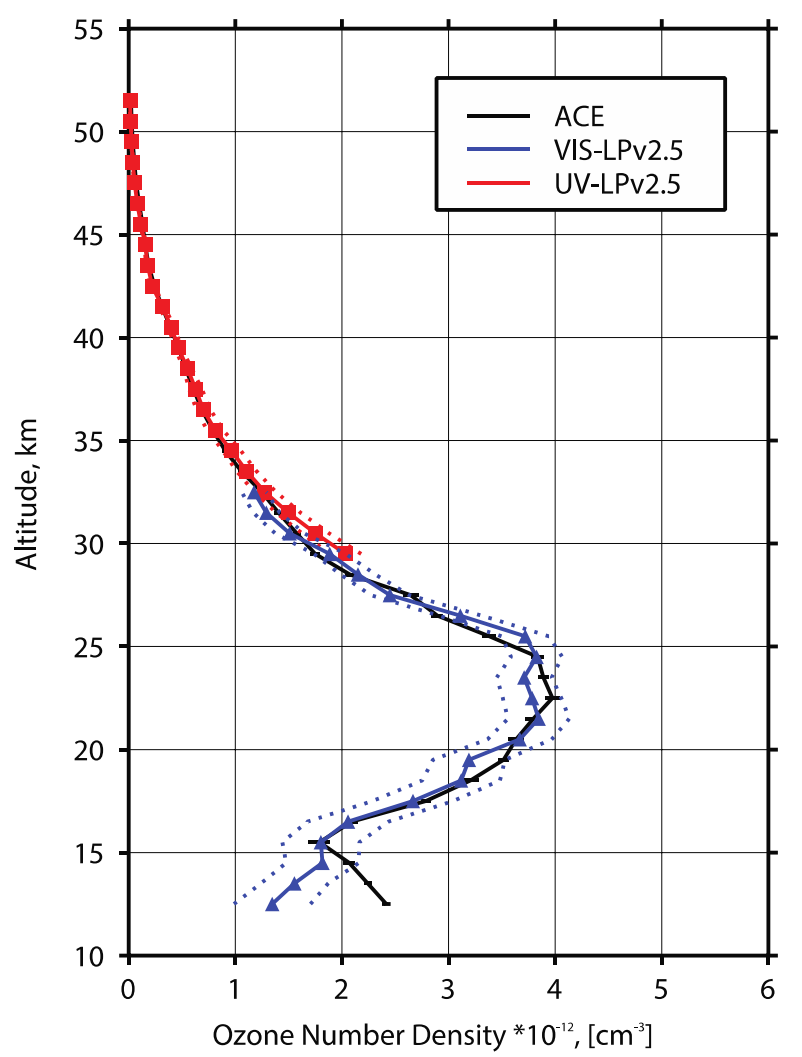

Ozone $04 / 23 / 2014,[60 \mathrm{~S}, 20 \mathrm{E}], \mathrm{dt}=2.0$ hours, dist $=98.0 \mathrm{~km}$

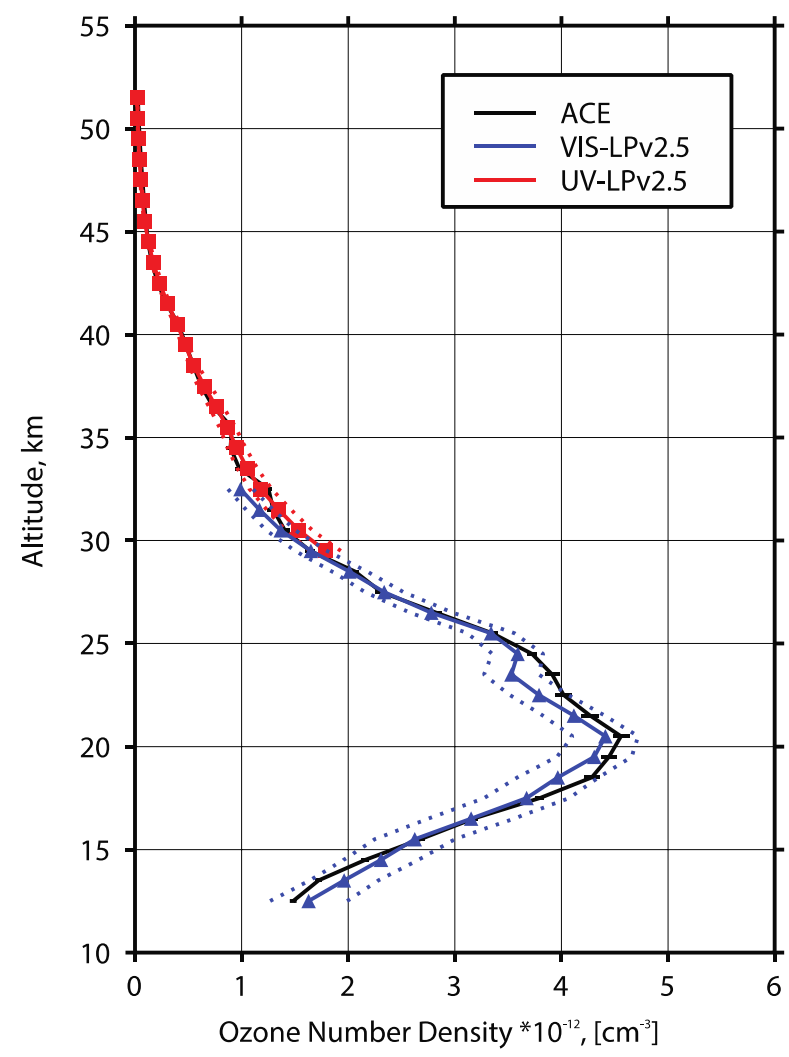

Figure S7. Matching ozone profiles from OMPS LP and ACE-FTS. The LP algorithm is designed to independently retrieve ozone profiles from UV (red) and VIS (blue) measurements. Precisions for LP measurements are shown as dotted lines. Black solid lines show ACE-FTS retrievals with the horizontal bars that correspond to the reported ACE precisions. Dates, coordinates and temporal and spatial differences between two satellite observations are indicated in the figure's titles. 

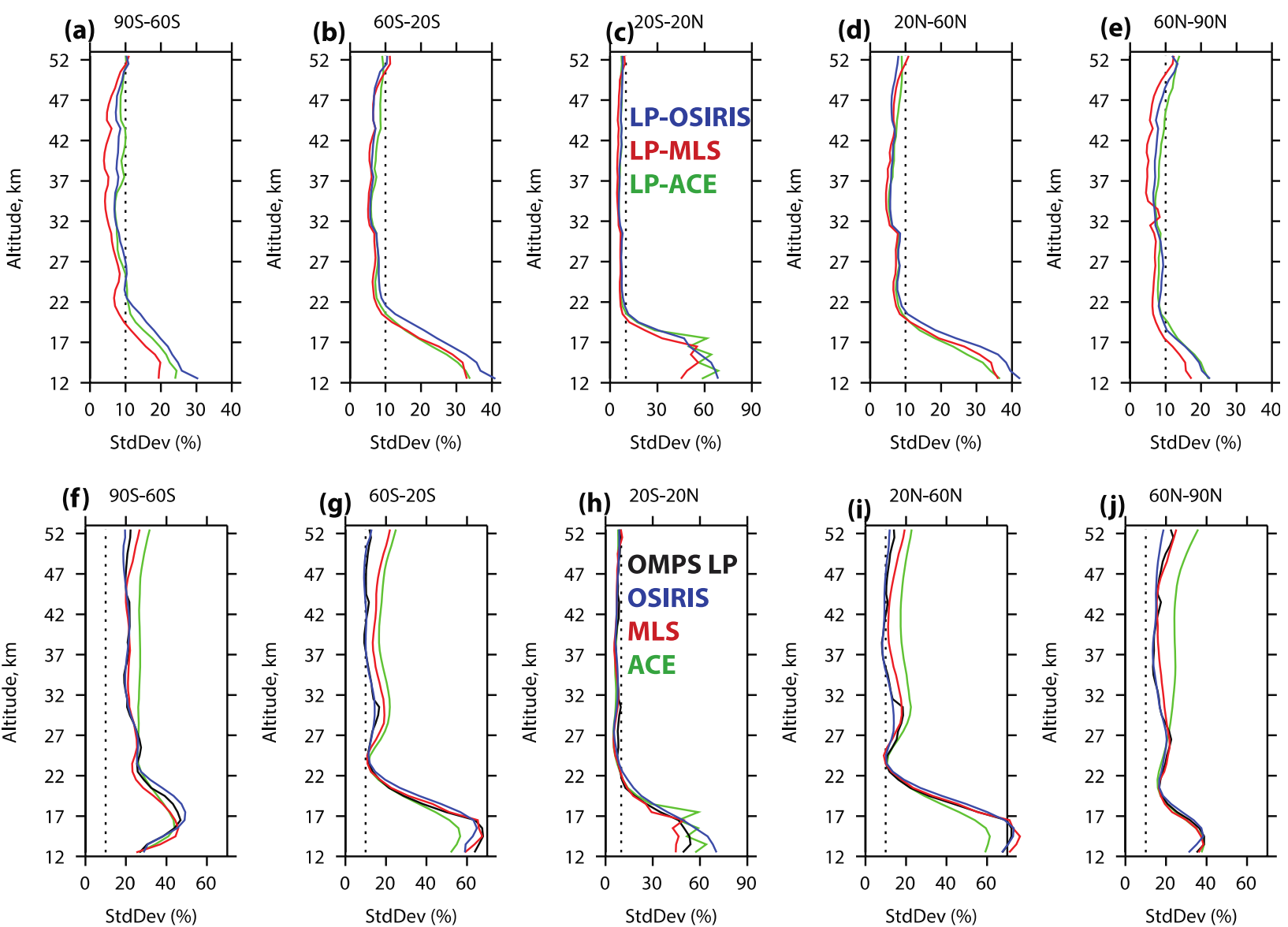

Figure S8. Upper panels (a-e) show standard deviations $1 \sigma$ for differences between OMPS LP version 2.5 ozone retrievals and correlative satellite measurements as functions of altitude in five wide latitude bins. Different colors on the upper panels (a-e) correspond to different instrument pairs: red for LP-MLS; blue for LP-OSIRIS; and green for LP-ACE. Lower panels (f-j) present ozone variability calculated for each instrument (OMPS in black, MLS in red, OSIRIS in blue, and ACE in green) as $1 \sigma$ standard deviation relative to the instrument mean.

(a)
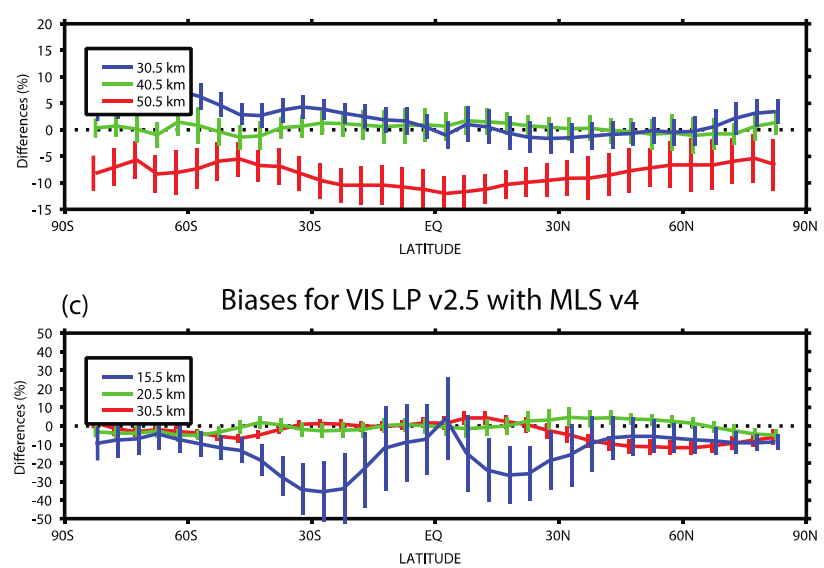

(b) Biases for UV LP v2.5 with OSIRIS v5.10

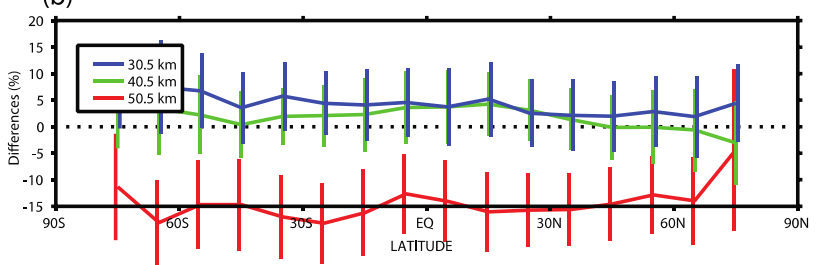

(d)

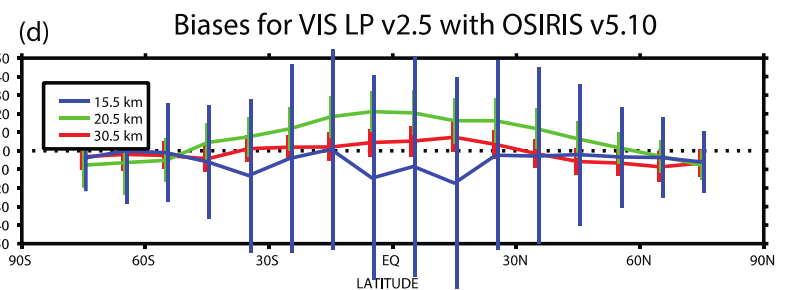

Figure S9. Biases for OMPS LP version 2.5 as functions of latitude against MLS and OSIRIS at several altitude levels. Upper panels (a-b) show biases for the UV ozone retrievals at $30.5,4.5$ and $50.5 \mathrm{~km}$, and lower panels (c-d) present biases for the VIS retrievals at 15.5, 20.5 and $30.5 \mathrm{~km}$. Error bars mark $1 \sigma$ standard deviations of the differences. 
Biases in 31.5-52.5 km partial columns (\%), OMPS UV

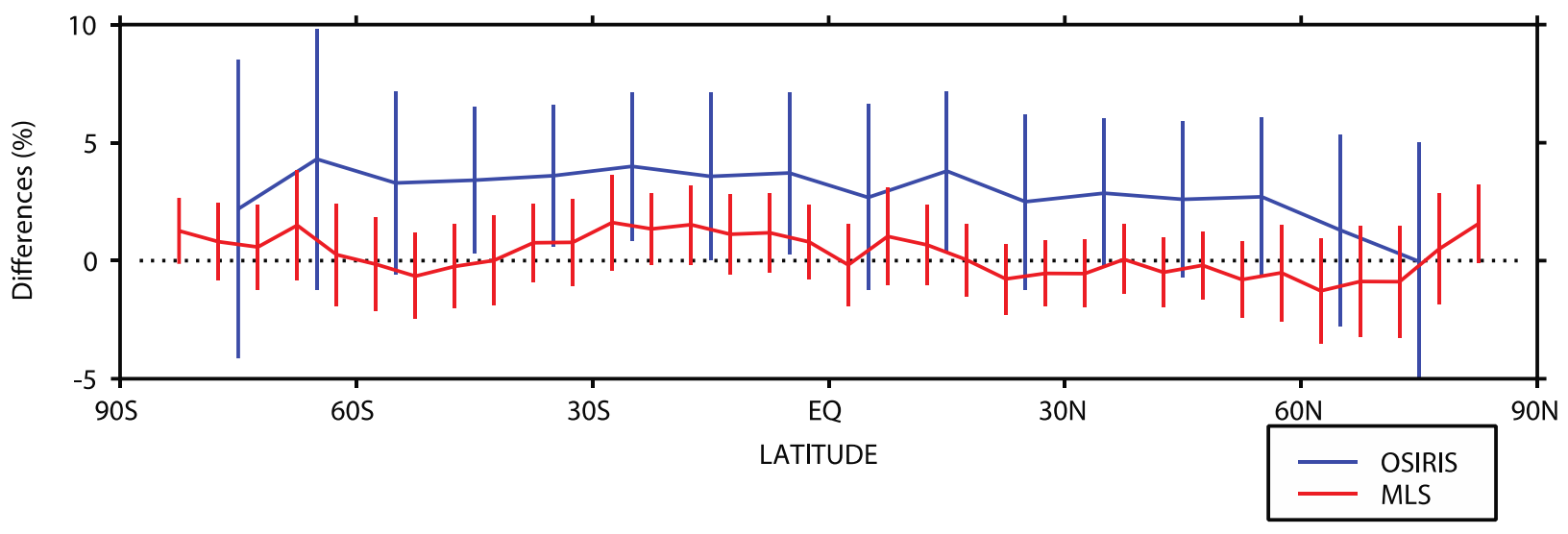

Biases in 12.5-30.5 km partial columns (\%), OMPS VIS

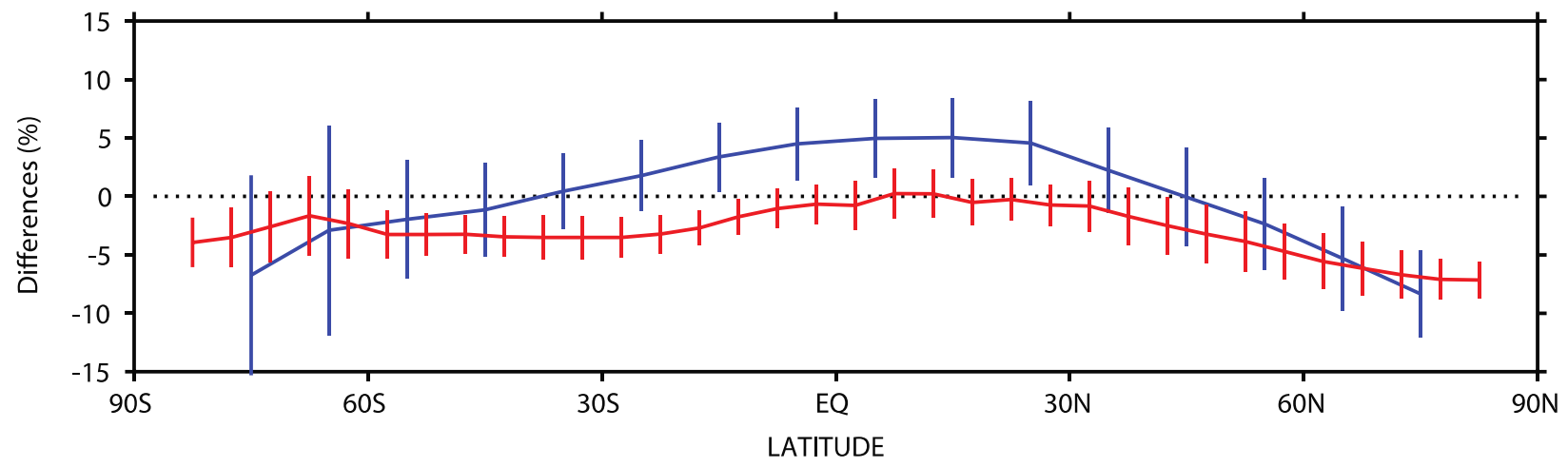

Figure S10. Mean biases for OMPS LP version 2.5 ozone partial columns against MLS and OSIRIS as functions of latitude. Top panel shows mean biases for the partial columns between $31.5 \mathrm{~km}$ and $52.5 \mathrm{~km}$, and the lower panel presents mean biases for the columns between 12.5 and $30.5 \mathrm{~km}$. Vertical bars indicate $1 \sigma$ standard deviations of the differences.
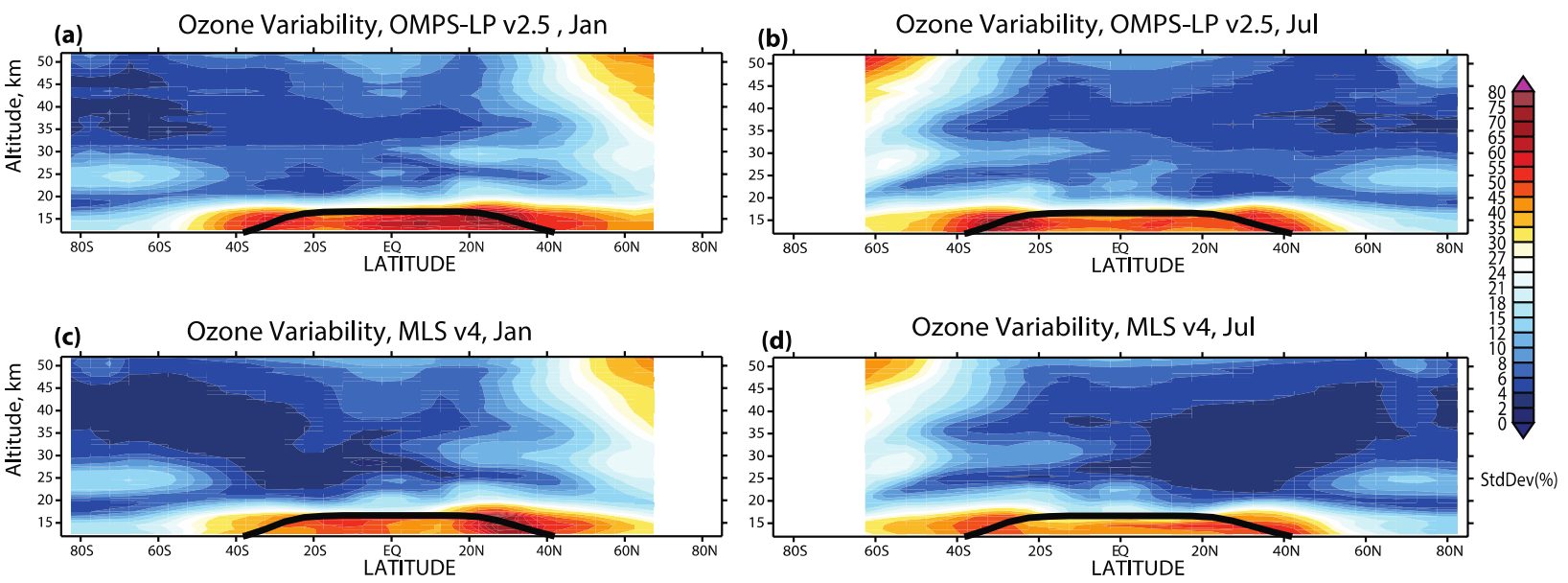

Figure S11. Typical ozone variability (\%) in January (a,c) and July (b,d) derived from OMPS LP (a,b) and Aura MLS (c,d) measurements as a function of latitude and height. The variability is calculated as $1 \sigma$ standard deviation from all individual ozone retrievals in a given month relative to the seasonal mean. 

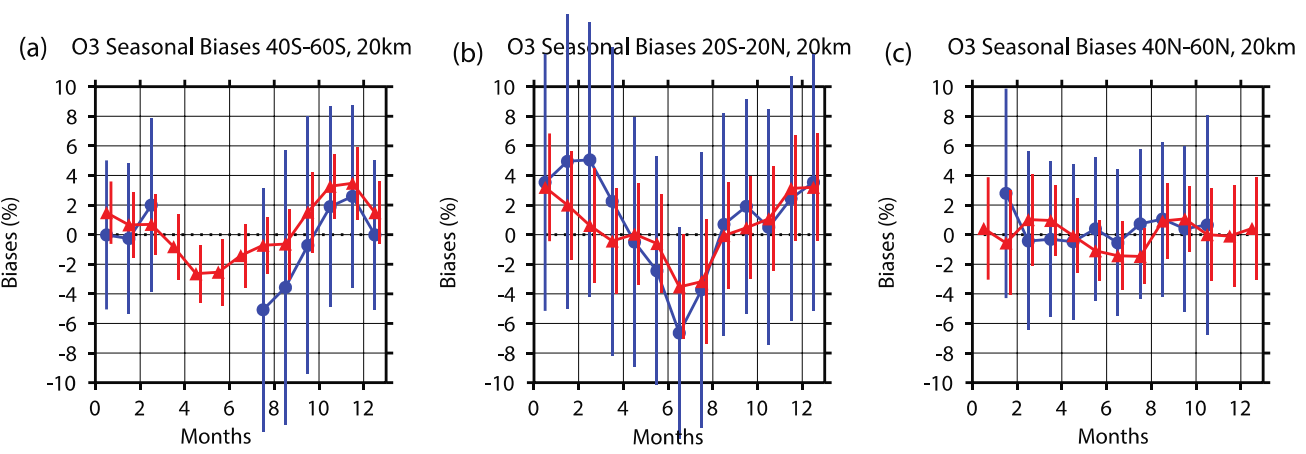

(d) 03 Seasonal Biases 40S-60S, 30km

(e) O3 Seasonal Biases $20 \mathrm{~S}-20 \mathrm{~N}, 30 \mathrm{~km}$

(f) 03 Seasonal Biases $40 \mathrm{~N}-60 \mathrm{~N}, 30 \mathrm{~km}$
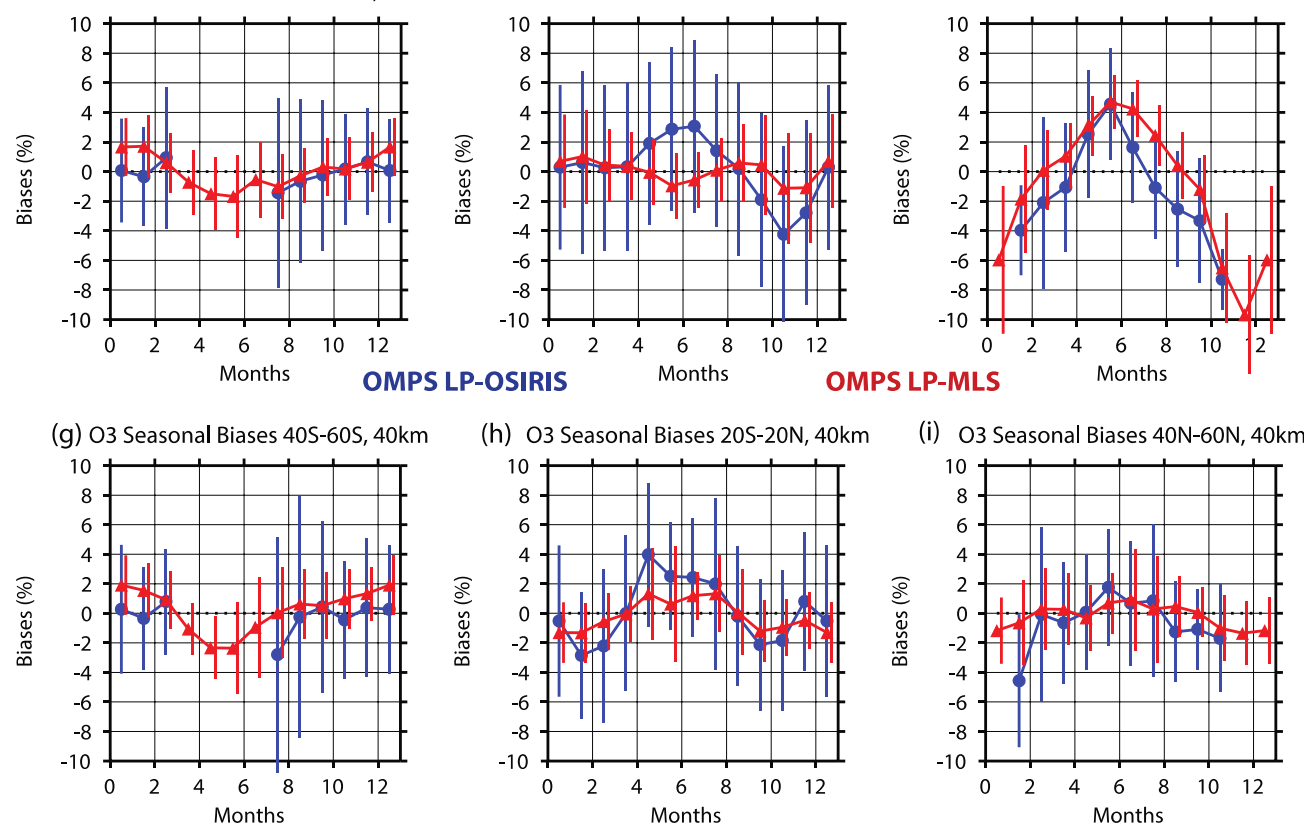

(i) $\mathrm{O} 3$ Seasonal Biases $40 \mathrm{~N}-60 \mathrm{~N}, 40 \mathrm{~km}$
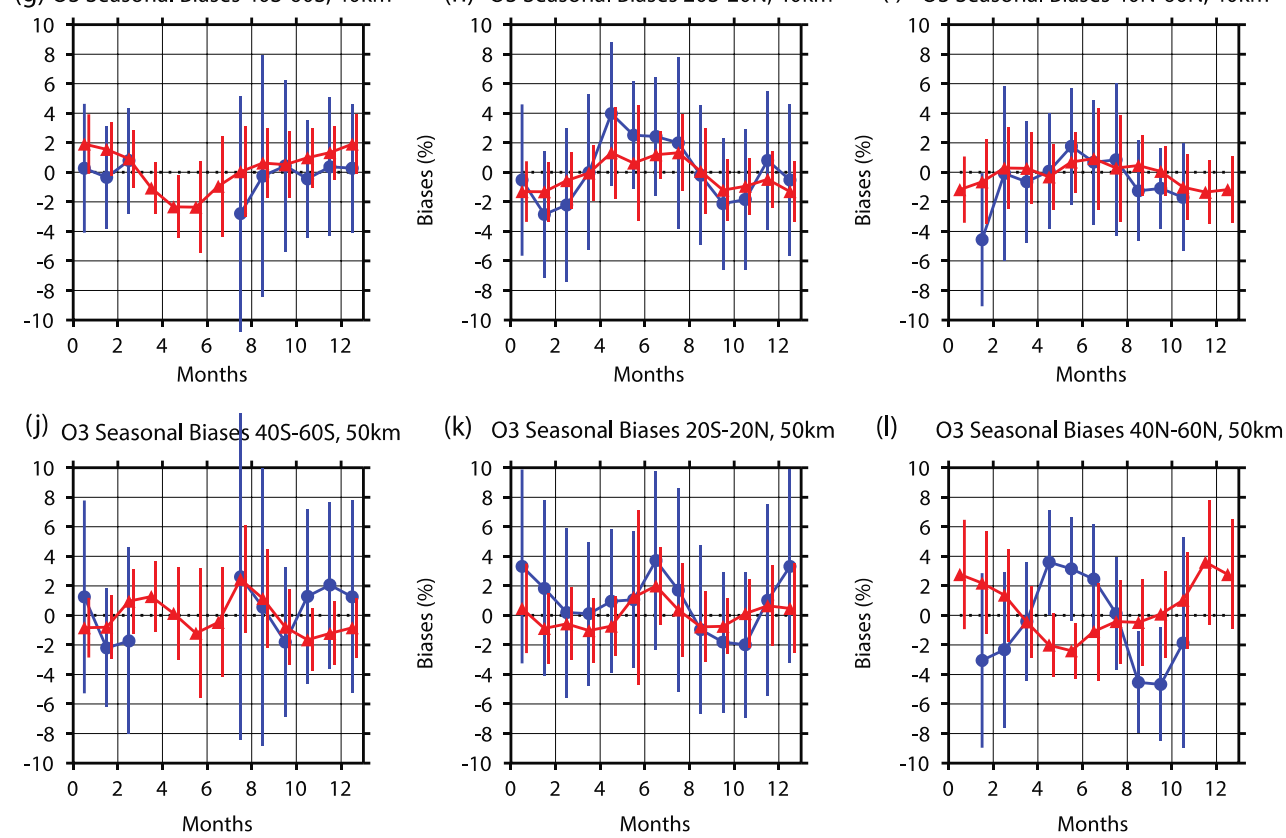

Figure S12. Residual seasonal biases between OMPS LP and Aura MLS (red lines) and OMPS LP and OSIRIS (blue lines). Residual seasonal biases are calculated as the mean differences between all matching profiles in a given month after the mean bias between two datasets had been removed. The vertical error bars show $1 \sigma$ standard deviations. The remaining seasonal biases typically do not exceed $5 \%$ and mostly are not statistically significant. The larger biases (that are also consistent between LP/MLS and LP/OSIRIS) are observed at $30 \mathrm{~km}$ in the northern mid-latitudes $\left(40^{\circ} \mathrm{N}-60^{\circ} \mathrm{N}\right)$, where there is a known instrumental issue with OMPS LP, which tends to vary seasonally. 

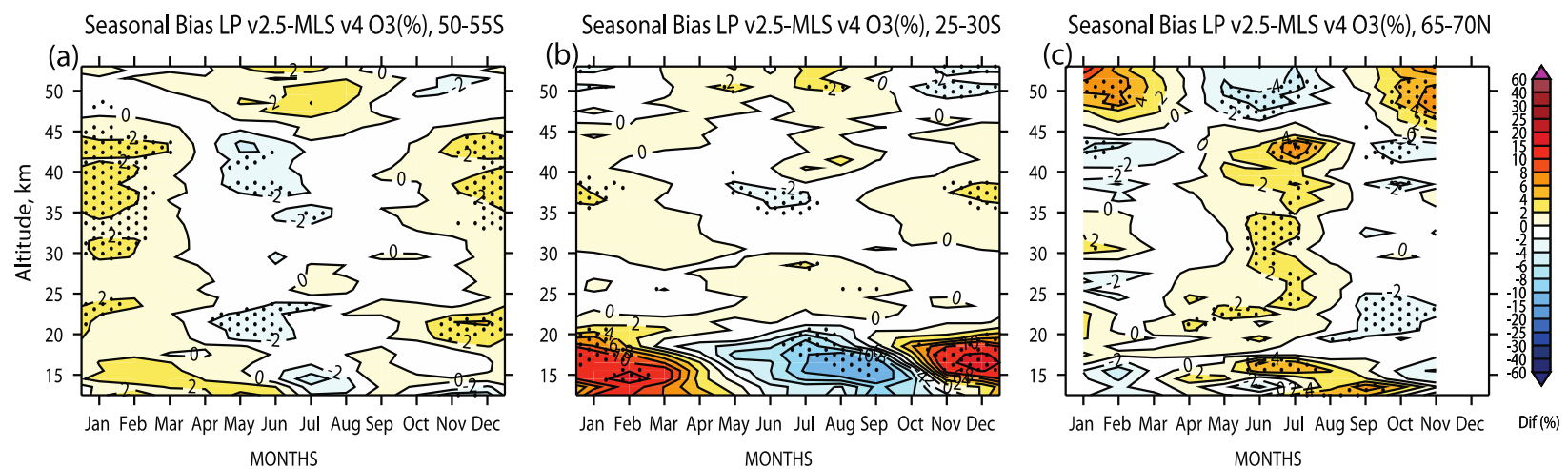

Figure S13. Residual seasonal biases (after the mean bias has been subtracted) between OMPS LP and Aura MLS as a function of season and altitude. Shaded area indicate places where seasonal biases are statistically significant within $1 \sigma$ standard deviation.

(a) Differences between 31.5-52.5 km partial ozone columns OMPS-LP v2.5 with MLS 4

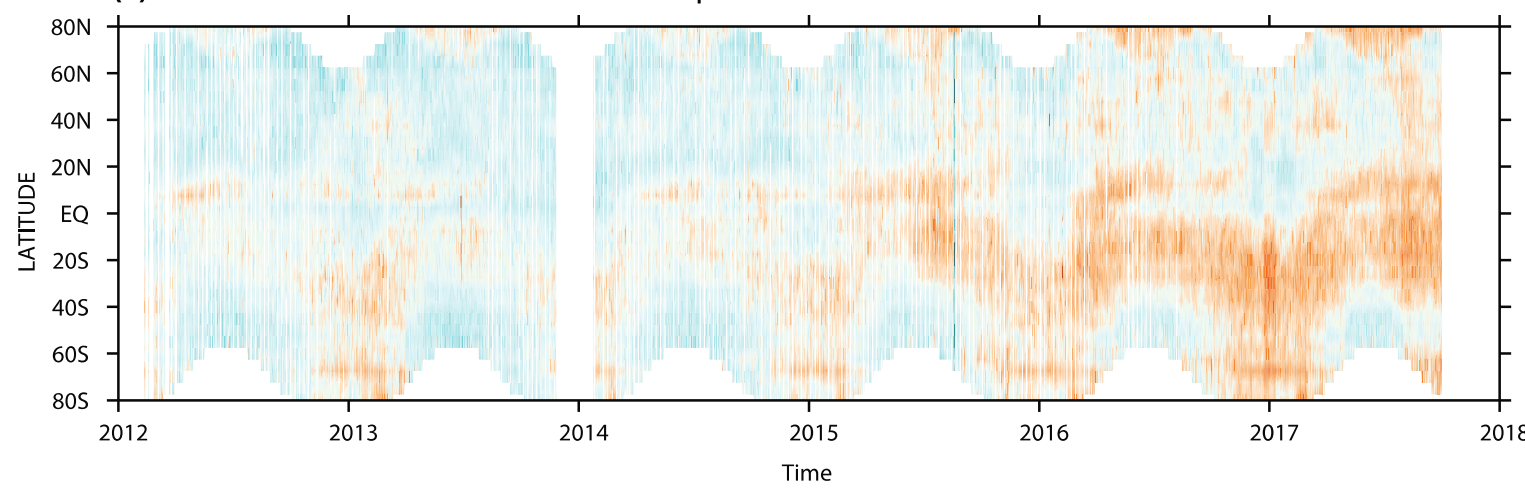

(b) Differences between 31.5-52.5 km partial ozone columns OMPS-LP v2.5 vs OSIRIS v5.10

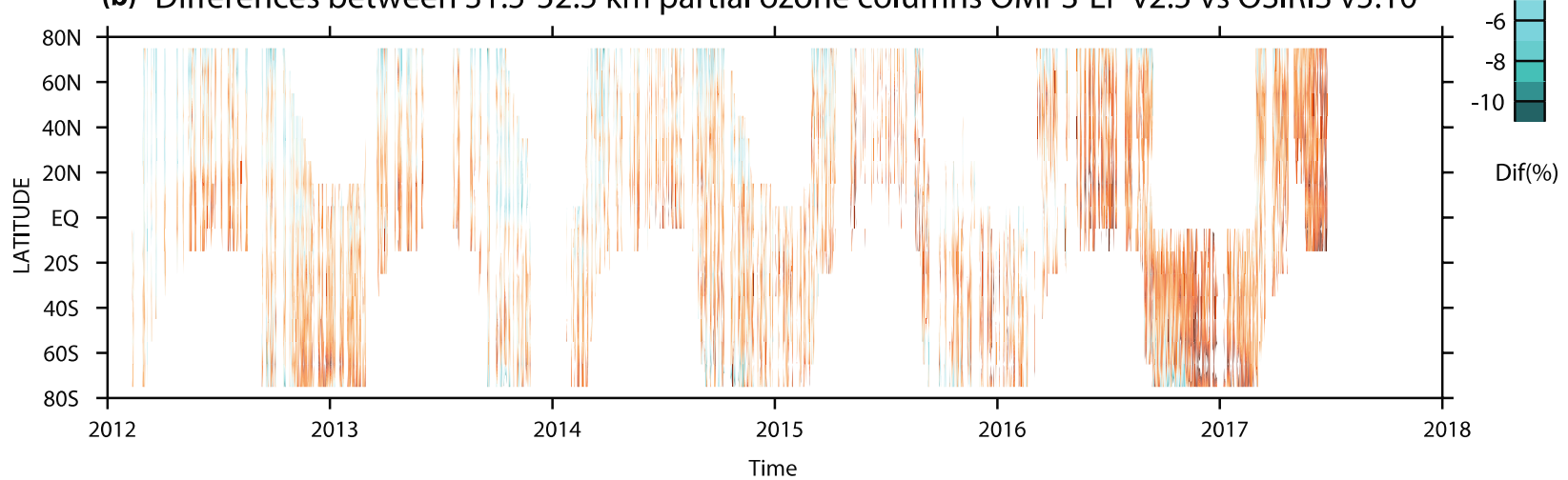

Figure S14. Daily zonal mean time series of differences between OMPS LP partial ozone columns between 31.5 and $52.5 \mathrm{~km}$ and corresponding quantities from OSIRIS and MLS as functions of time and latitude. Upper panel shows differences for ozone partial columns against MLS (a), and lower panel against OSIRIS (b). This figure shows that since $\sim 2016$ the differences in ozone tend to be more positive compared to the previous time period. 

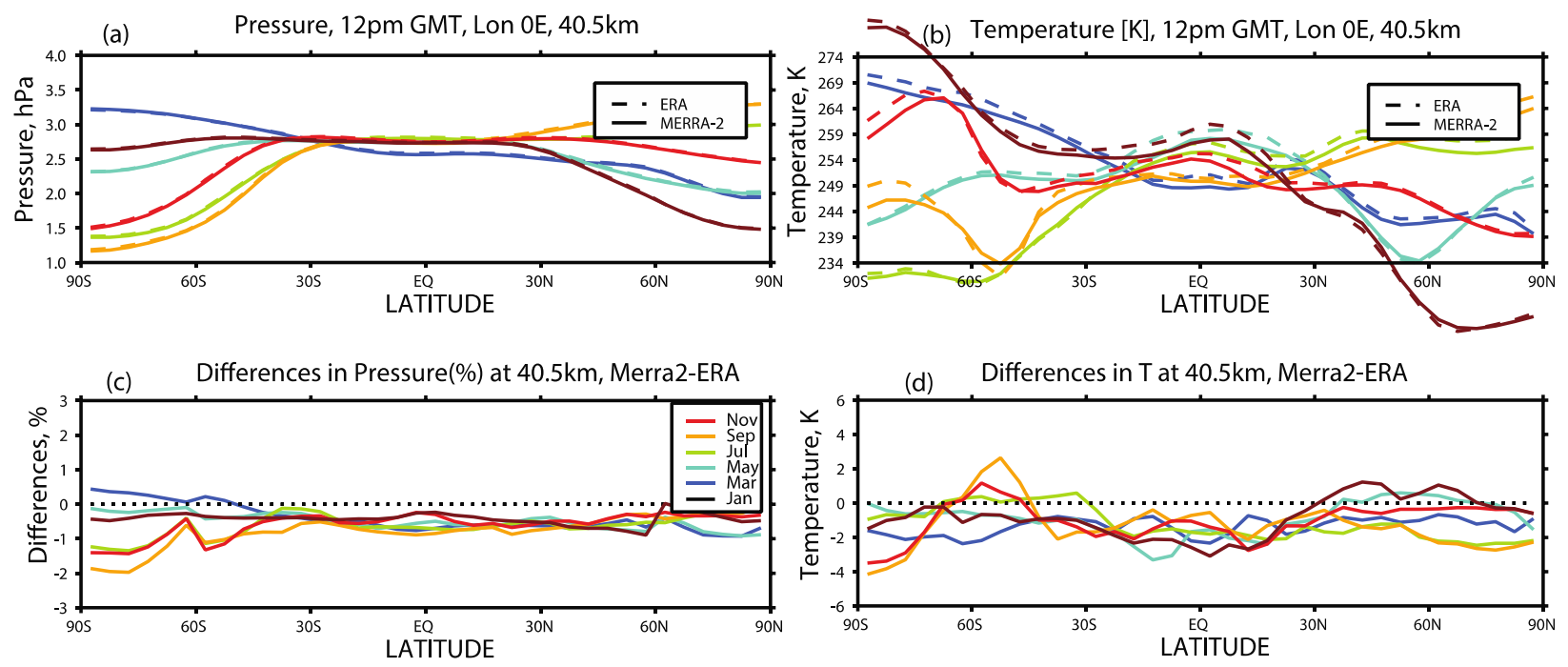

Figure S15. Summary of comparisons between MERRA-2 (Forward Processing Instrumental Team) and ERA-Interim reanalysis. Top panels show monthly mean pressure (a) and temperature (b) values as a function of latitude at $40.5 \mathrm{~km}$ from two reanalysis. Different colors correspond to different months of 2016. MERRA-2 values are shown as solid lines and ERA-Interim as dashed lines. Lower panels show differences between MERRA-2 FP and ERA-Interim values for pressure (c) and temperature (d). 